adjacent to an epileptogenic lesion. Unlike EEG, MEG is restricted to interictal recordings, but the procedure is noninvasive. This study demonstrates that the accuracy of MEG localization of epileptogenic foci is equal to that of the invasive ictal EEG recordings.

\title{
LANGUAGE RECOVERY AFTER LEFT HEMISPHERECTOMY
}

The language proficiency of 6 right-handed children (ages 7-14 years) with Rasmussen's syndrome, who underwent left hemidecorticectomy after 5 or more years of normal language development before seizures, were investigated at the Johns Hopkins Hospital, Baltimore, MD. The ability to discriminate consonants and vowels was improved within 4 to 16 days after surgery, when compared to that before surgery, whereas other language functions remained severely impaired until 6 months. Word repetition and phrasal comprehension recovered fully within 1 year, while expressive functions and naming were delayed, and spontaneous speech was telegraphic and restricted to single words. All patients could walk unaided, but had little use of the right arm or hand. Seizures were controlled and antiepileptic drugs were withdrawn in 3.

Rapid recovery of receptive language after surgery suggests that the intact right hemisphere has an innate dbility to analyse phonemes and discriminate consonants and vowels. Delayed and partial recovery of expressive language functions may be attributed to plasticity of the right hemisphere, persisting after 5 years of age, the proposed critical age for completion of language acquisition and lateralization. (Boatman D, Freeman J, Vining E et al. Language recovery after left hemispherectomy in children with late-onset seizures. Ann Neurol Oct 1999;46:579-586). (Respond: Dr Boatman, Department of Neurology, Johns Hopkins Hospital, 600 North Wolfe Street, Meyer 222, Baltimore, MD 21287).

COMMENT. Explanations offered for the immediate improvement in phoneme discrimination after left hemispherectomy in these patients included: 1) the innate receptive language capability of the right hemisphere; and 2) a bilateral representation of phoneme processing, at least until adolescence. The right hemisphere is capable of functioning when receptive, and to some extent expressive, language abilities have been undermined by seizures and damage to the left hemisphere in young children.

\section{EARLY ONSET SEIZURES BEGET SEIZURES}

The long-term effect of early-life seizures on later seizure-induced neuronal damage and behavior was investigated in the laboratory using systemic kainate to induce seizures in rats at the Massachusetts General Hospital, Boston, MA. Memory was tested using a Morris water maze, and brains were examined histologically for evidence of injury. Seizures induced during the second week of life (15 days) were not associated with brain injury or cell death, but they predisposed animals to extensive neuronal injury and impairment of learning when seizures were again induced in adulthood (45 days). (Koh S, Storey TW, Santos TC, Mian AY, Cole AJ. Early-life seizures in rats increase susceptibility to seizure-induced brain injury in adulthood. Neurology September 1999;53:915-921). (Reprints: Dr Andrew J Cole, Epilepsy Service, Massachusetts General Hospital, VBK 830, 55 Fruit Street, Boston, MA 02114).

COMMENT. These laboratory studies confirm previously reported evidence that seizures in young experimental animals can be followed by delayed brain growth, and lowered seizure thresholds. (Theodore W, Wasterlain CG. Do early seizures beget epilepsy? Editorial. Neurology Sept 1999;53:898-899). The studies 